THÉMATA. Revista de Filosofía

$\mathrm{N}^{\mathrm{o}} 51$, Enero-junio (2015) pp.: 343-361

ISSN: 0212-8365 e-ISSN: 2253-900X

doi: 10.12795/themata.2015.i51.18

\title{
TRISTÁN E ISOLDA DE WAGNER Y LA FILOSOFÍA ROMÁNTICA. NOVALIS Y SCHOPENHAUER EN WAGNER
}

\section{TRISTAN AND ISOLDE OF WAGNER AND THE ROMANTIC PHILOSOPHY. NOVALIS AND SCHOPENHAUER ON WAGNER}

\author{
Antonio Ríos Rojas ${ }^{1}$ \\ Universidad de Salamanca (España)
}

Recibido: 20-10-2013

Aceptado: 21-04-2014

Resumen: Hacemos una incursión en el Tristán e Isolda de Wagner, estudiándolo a través de las ideas del amor romántico y sus conceptos afines de disolución, muerte y nada. El débito que esta ópera wagneriana tiene con la filosofía de Schopenhauer ha sido destacado por muchos comentaristas. En este escrito explicamos esta influencia, pero también daremos un giro para ver es Tristán e Isolda una obra que se desvía por completo de muchas ideas de Schopenhauer sobre del amor.

Palabras-clave: amor, disolución, hundimiento, suicidio, aire.

\begin{abstract}
We make an incursion into "Tristan and Isolde" by Wagner and examine it from the idea of romantic love, with its very close concepts of dissolution, death and nothingness. As Tristan's Schopenhauerian approach is always highlighted, here we propose a further study and see in what way Tristan is a work which deviates greatly from many of the ideas of Schopenhauer.

Key-words: love, dissolution, decay, suicide, air.
\end{abstract}

[1] (a_riosrojas@hotmail.com) Doctor en Filosofía por la Universidad de Salamanca y Profesor de Filosofía en la Enseñanza Secundaria. Es autor del libro: Tolstoi. Su vida y su obra, Rialp, Madrid, 2015, y de artículos sobre Peter Sloterdijk (Revista Observaciones filosóficas), Richard Wagner (Revista de occidente), y numerosos artículos sobre Filosofía Medieval (Revista española de Filosofía Medieval). 
En su Tratado de la pasión, Eugenio Trías centra el acontecimiento decisivo de la historia de Tristán e Isolda en un instante que no queda reflejado de forma rotunda en la ópera de Wagner. Ese instante clave destacado por Eugenio Trías lo deja aparecer Wagner de forma secundaria en el transcurso de la ópera, haciendo que Isolda lo cuente a su sirvienta Brangania en el primer acto. Ese instante es anterior a la ingesta de la fatídico-bendita pócima del amor, y para Trías es este el acontecimiento fundamental que hace nacer verdaderamente el amor entre ambos. He aquí el acontecimiento: Un extranjero herido, "Tantris", es conducido ante Isolda, ésta da cobijo y cura al moribundo, pero poco después descubre que el extranjero es en realidad "Tristán", quien ha dado muerte al rey Morold, prometido de Isolda. Al reconocer esto, Isolda alza la espada para hundirla en el pecho del guerrero moribundo, pero en ese instante los ojos de Isolda se desvían y se encuentran con los ojos sufrientes y hermosos del guerrero. Isolda deja caer la espada, abatida ya por el amor ${ }^{2}$. A nadie, ni tan siquiera a su fiel Brangania, había confesado antes Isolda ese germen irrefrenable de amor, aquel instante en el que los ojos del uno y del otro se encuentran quedando presos de amor.

La ingesta del filtro amoroso no es, pues, el hecho decisivo, aunque es el que desencadena todos los acontecimientos fatales que presentarán al amor como "Amor Tirano", como una fuerza que se apodera de los destinos de Tristán y de Isolda. Aunque la ingesta del filtro, ya en el poema original medieval de Von Strassburg, apresa a los amantes en las cadenas del amor, nosotros leeremos de forma distinta dicho amor en la ópera de Wagner.

Por mucho que pudiéramos imaginarnos que la pócima de amor, como la pócima de muerte, como la de curación de las heridas -todas ellas transporta Isolda en su arcón- pudieran estar hechas de elementos "naturales", no muestran en el fondo sino la esencia del artifico, de la magia. La mezcla y modificación de substancias - hoy llegadas a puntos extremos en medicinas sintéticas o drogas sintéticas- es lo que romperá las cadenas de una naturaleza -de las "naturalezas" de Tristán y de Isolda- que se encuentra asediada y controlada por la cultura en todos sus flancos, taponada en todos sus poros por la fuerza de la costumbre (cultura). Ante ello el romántico quiere volver a ser esencialmente naturaleza o, en muchos casos, armonizar incluso esa separación entre naturaleza y cultura. La droga ingerida, la pócima de amor, es lo que de una forma mágica desvela la supuesta naturaleza, rasgando y quemando el velo de la cultura y sus siervos. Expresándonos en términos de comienzos del siglo XX diriamos: la ingesta de la pócima rompe las cadenas de la represión de las naturalezas "Tristán" e "Isolda", rompiendo el hecho de que Tristán e

[2] Trías, E: Tratado de la pasión. Debolsillo; Barcelona, 2006; p.85. En la fuente original de Von Strassburg encontramos este instante en: Strassburg, G. von: Tristán und Isolde. Verlag Neues Leben, Berlín, 1975, p.30.

[3] Strassburg, G. von: o.c; p.32-33.

THÉMATA. Revista de Filosofía, Nº51 enero-junio (2015) pp.: 343-361

doi: 10.12795/themata.2015.i51.18 
Isolda pertenecieran a pueblos enemigos, rompiendo el hecho posterior de que Tristán haya raptado a Isolda para ofrecerla a su buen rey Marke, al que debe fidelidad, y rompiendo el hecho de que Isolda sepa ya que Tristán fue el que dio muerte a su rey de Irlanda, con quien tenía que desposarse. Todos estos velos los rasga la daga que es ese artificio mágico. La droga amorosa derriba toda barrera y todo límite, pero nótese -y es esto lo que ante todo destacamos- que el amor ya se había despertado en ellos mucho antes, justo en aquel instante en que ambos por primera vez se miraron a los ojos.

En la vida real, Novalis quiso inventar un tipo de alquimia que devolviera la vida a su amada Sophie von Kuhn para existir así eternamente con ella ${ }^{4}$, la vida artística, en cambio, no necesita de tanto esfuerzo alquímico, de tanto desvelo, pues Isolda lleva ya el artificio mágico en la bodega del barco.

La ruptura de la represión no hace que Wagner conduzca a sus personajes a la animalidad sin límites, como muchos entienden el significado de desinhibición, sino que conduce al nacimiento del Amor-Arte. Wagner quiere llevar a Tristán y a Isolda a ser una misma esencia. En el plano del arte intuitivo y contemplativo esta perfecta armonía se produce, según Schopenhauer, cuando sujeto y objeto de conocimiento se hacen uno, dejando el sujeto de ser volitivo y fundiéndose con el objeto contemplado, que deja de ser visto bajo las condiciones del principio de razón y pasa a ser plena Idea. Esta fusión serena puede darse en el arte intuitivo porque en él se trata de confrontar un sujeto con un objeto, para que el primero deje de ser reo del querer y el segundo pueda convertirse en apaciguadora y reposada Idea. Estos pensamientos tratados en el Libro III de El mundo como voluntad y representación no pueden manifestarse en Tristán e Isolda porque ambos son sujetos, voluntad, y nunca dejan de ser sujetos. La tragedia del amor romántico es que no permite lo que se quisiera en el fondo: la unidad quieta y reposada del arte contemplativo-intuitivo, pues ambos componentes del amor son y permanecen sujetos, voliciones puras e imparables. Pero pese a todo, de forma patente, vemos el deseo de Tristán e Isolda -y de todo amor romántico- de intercambiarse papeles de objeto y sujeto, es decir de acallar la voluntad, de fundirse plenamente como se funde el sentimiento artístico. A ese punto quiere conducir Wagner a Tristán y a Isolda, aunque el acallar la voluntad sólo tenga lugar con la negación del vivir. Schopenhauer sabe que esa unión de tipo artístico, intuitivo-contemplativo es sólo momentánea, se da en un instante para desaparecer pronto y dejarnos sumidos de nuevo en el esclavo círculo de lo cotidiano, a merced siempre del principio de razón. Por otro lado, ¿Se trata verdaderamente en el Tristán de convertir a dos amantes en sujetos avolitivos del conocimiento? ¿No son ellos, más bien, la expresión pura e imparable de la voluntad? Precisamente esta última fue la solución que escogieron los primeros intérpretes de la obra: al

[4] Safranski, R: Romantik; Fischer Verlag, Frankfurt am Main, 2010, p.117-118.

THÉMATA. Revista de Filosofía, Nº51 enero-junio (2015) pp.: 343-361 doi: 10.12795/themata.2015.i51.18 
ser Tristán e Isolda ejemplos puros de voluntad, estos primeros intérpretes de la ópera creían que el Tristán no fue compuesto bajo la influencia de Schopenhauer y que más bien significaba lo opuesto a su filosofía ${ }^{5}$. Una crítica a esta interpretación masiva de la ópera ya fue destacada por Thomas Mann. Si la filosofía de Schopenhauer significa el vencimiento de la imparable e hiriente voluntad, Thomas Mann ha visto en el Tristán: un poema erótico y místico en elogio y adoración del sueño, el paraíso del descanso, el sagrado silencio de la pasividad $^{6}$. La fusión de ambos (Tristán e Isolda) no es tanto expresión de la voluntad, de vida, cuanto expresión de desintegración de la misma voluntad. Pero esta negación de la voluntad no implica acallar el amor, sino que precisamente -tal como considera Schopenhauer- el amor se muestra como un principio cosmogónico de comienzo y fin de todas las cosas, de vida y de muerte. Thomas Mann ha destacado que la obra de Schopenhauer es erótica por naturaleza $^{7}$, y desde este foco del erotismo como principio de creación y de muerte es como nosotros leeremos Tristán e Isolda.

Quede anunciado de antemano que daremos un matiz más oscuro a la claridad cosmogónico-amorosa pretendida por Thomas Mann en Tristán e Isolda. Para nosotros Tristán e Isolda son naturalezas a medio camino entre lo humano-consciente y la piedra inorgánica que se hunde debido a la ley de la gravedad. Diríamos que ellos son conscientes de que se hunden al amar, y de que el amor no tiene propiamente otro fin que el de desvelar el hundimiento de la consciencia.

\section{"Y"}

La condena que se produce al tomar la pócima no es la condena de amar. Amar es aquí tan sólo el comienzo necesario de lo realmente anhelado por Tristán e Isolda: la muerte, la desintegración y la disolución. Muerte, desintegración y disolución que el romántico no siente del todo como tragedia, sino casi como triunfo, como un necesario paso a un "más allá", pues la muerte misma es concebida por el romántico como un acto de creación".

La tragedia del amor romántico consiste en que debe ser pleno y para ello los amantes han de ser uno, ambos deben abandonar su ser como individuos, lo que en el fundamentalismo romántico implica la muerte. Esa muerte es la que Wagner anticipa con su alucinado tratamiento orquestal de la ópera, una música

[5] Cf. Mann, T: "Sufimientos y grandeza de Richard Wagner"; en: T. Mann: Freud, Goethe, Wagner, Tolstoi; editorial Poseidón, Buenos Aires, 1944; p.182 y 186.

[6] Mann, T: o.c; p.184.

[7] Mann, T: o.c; p.187.

[8] Cf. Argullol, R: El héroe y el único; Acantilado, Barcelona, 2008, p.446.

THÉMATA. Revista de Filosofía, No 51 enero-junio (2015) pp.: 343-361

doi: 10.12795/themata.2015.i51.18 
infinita con acordes interminables, que expresan la tragedia de querer ser siempre uno, la tragedia de que amar plenamente implica asfixia y finalmente muerte. Sin embargo, ese ser Uno-Perfecto tendrán que serlo dos sujetos, volitivos en su origen hasta el extremo. El amor tiene lugar entre dos amantes y no entre una idea y un sujeto avolitivo. Que dos sujetos sean uno plenamente significa que cada cual tenga que morir en el otro al romper la individualidad que sienten como cadenas, por ello tienen que romper la conjunción "y" ("e") de Tristán "e" Isolda. En el segundo acto de la ópera ambos caen en la cuenta de que no son dos individuos, y que la conjuntiva no tiene ya razón de ser. Convertirse en masa es de lo que se trata aquí a través de este anhelo de unidad y de negación de la individualidad. La esencia y finalidad de la masa es anular toda conjuntiva, toda individualidad. Elias Canetti diferencia entre masa abierta y masa cerrada ${ }^{9}$. Tristán e Isolda son una micromasa cerrada. El enamoramiento, llevado al extremo en el que ellos lo sienten, no muestra otra cosa sino la esencia de la masa. No la masa expansiva e inclusiva que arrolla o engulle todo lo que encuentra a su paso, sino la masa cerrada que se contrae en este caso hasta no dejar huecos externos por donde respirar. La muerte de Isolda y de Tristán acontece por asfixia, por haberse separado de la atmósfera, por contracción ante la atmósfera. Tristán e Isolda tienden con ello a lo monstruoso, a convertirse en siameses unidos por el sistema respiratorio. Todo el segundo acto y casi todo el tercero podríamos comprenderlo como el proceso dramático wagneriano de cerrar ventanas y puertas, como una huida de lo externo y de su atmósfera. Tristán e Isolda quieren "hundirse y ahogarse". Era sin duda en esta época más poético expresar la muerte por ahogamiento que por asfixia, recordemos que Luís II de Baviera escoge al modo de Isolda el suicidio por inmersión-ahogamiento. La inmersión, hundimiento, ahogamiento respondía al sentido romántico de morir creándose, haciéndose uno, volviendo al uno del que se procedía. Aún el romántico del siglo XIX no era del todo consciente de su ser atmosférico, de su prosaica necesidad de aire. Cuando en 1915 tropas alemanas empleen gases venenosos contra las trincheras contrarias no le cabrá más duda al ser humano de su esencia atmosférica, y menos aún con las cámaras de gas y la radioactividad producida en Hiroschi$\mathrm{ma}^{10}$. De haber conocido todo esto, Wagner se habría expresado probablemente en términos atmosféricos de asfixia y no de ahogamiento, aunque hay momentos en los que el texto de Wagner alude explícitamente a la asfixia. Brangania al final de la ópera exige a Isolda: Respira! Vive! Isolda: ¿Debo respirar? Pero en que Wagner no expresara en términos de asifixia la muerte de amor, supo muy bien jugar malévolamente con las gargantas de los protagonistas y de los oyente de su obra.

[9] Cf. Canetti, E: Masse und Macht; Büchergilde, Frankfurt am Main, 1988; p.14; edición en español: Masa y poder; Debolsillo; Barcelona, 2010; p. 71.

[10] Cf. Sloterdijk, P: Esferas III; Siruela; Madrid, 2006; p.75-116.

THÉMATA. Revista de Filosofía, Nº51 enero-junio (2015) pp.: 343-361

doi: 10.12795/themata.2015.i51.18 
Hoy, no sólo un atento poeta contemporáneo, sino incluso un forense podría atestiguar las muertes "por asfixia" de Tristán y de Isolda. El desvanecerse, el "hundirse" final de Isolda, los últimos acordes de su muerte de amor, uno de los momentos más conmovedores de la historia de la creación humana, no es otra cosa que el estado de inconsciencia en el que entra el que se asfixia en el momento previo a la muerte, todo es ya descanso en este intervalo, incluso todo es paz. El melancólico dolor, la nostalgia, la voluntad, todo ello se calma en esos últimos acordes, tras de los cuales al oyente le cuesta respirar, pues al término de la ópera el oyente se siente como el anestesiado que despierta jadeante y a media respiración. El oyente volverá a su estado cotidiano, irá entrando poco a poco en el mundo de la vida, abandonando ya a Tristán e Isolda en su reino de disolución y de muerte por asfixia. En el Tristán, Wagner no sólo ha alcanzado cotas insólitas en el mundo de la música y del drama, sino que también se ha mostrado como el músico más consciente de la respiración humana, de que vivimos en y de aire. Él separa el mundo del aire, en el que se da la luz y la vida del mundo de las profundidades - del aislamiento, de la monstruosidad- hacia las que quieren llegar Tristán e Isolda, separándose del aire. También respecto al espectador, pues el Tristán está concebido para que el espectador sufra con los protagonistas, y los acordes del Tristán se aferran también a la garganta del oyente-espectador, y una mano aprieta ahora más el cuello del oyente al elevarse los violines a las notas altas, la misma mano que, apretando ahora menos, permite respirar, para volver a cerrarse con más fuerza en el cuello del oyente, curiosamente a través de las notas más bajas. Wagner es el primer experimentador musical que trata con el sistema respiratorio del oyente. En su genio inventa cámaras de oxígeno de notas y acordes en las que introduce al espectador y sabe cuando abrir y cuando cerrar las cámaras. Todo el que ha visto alguna vez una representación completa y bien interpretada de Tristán e Isolda, conscientemente o no, ha experimentado esto. Si el oyente llega a creer que las profundidades a las que se dirigen Tristán e Isolda, son atmósferas respirables, si llega a confundir con amor la disolución a la que, como individuos, ambos protagonistas se encaminan, entonces es que el narcótico comienza a hacer efecto también en el oyente.

La micromasa cerrada Tristán-Isolda es un cierre de puertas, un querer respirar sólo del aliento del otro, al modo de siameses unidos por la faringe, la laringe y la boca. El amor aquí expresado es la negación de la vida. La micromasa una anula e imposibilita toda separación, todo hueco, Tristán e Isolda tienden a ser siameses, no soportan su separación propia, pues ya han negado la conjuntiva "y", negando con ello toda contradicción, toda discusión, todo diálogo, por tanto, todo conocimiento objetivo. Han clausurado la posibilidad de la ciencia y del progreso, pero también de la memoria y del regreso. Su regreso no es posible sino como hundimiento, como caída. Sólo cayendo, sólo hundiéndose en las profundidades creen poder afirmarse en su ser. Pero como si fueran 
conscientes de su monstruosidad amorosa, antes que existir eternamente como siameses, ellos prefieren darse muerte. Trágicamente, lo monstruoso se hace consciente de que no puede vivir. La voluntad schopenhaueriana, incansable, imparable, esencia del mundo, tiende a encontrar reposo en el arte intuitivo-contemplativo, en la anulación de la volición que es la contemplación pura, tal como hemos apuntado. Desde luego no es el amor el ámbito en el que este descanso bendito tiene lugar, y el deseo de parar, de quietud que todo romántico y que sin duda Tristán e Isolda tienen, se hace inviable en vida, pues ellos son dos vivos, dos sujetos volitivos.

Como hemos indicado más arriba se tiende a destacar con exceso el débito de la filosofía de Schopenhauer en el Tristán, pero esto es cierto sólo en determinados aspectos. En El mundo como voluntad y representación, queda el mundo señalado como voluntad, como incansable voluntad y sólo el pleno vencimiento de ella es posible por la disolución, la muerte, la entrada en la nada ${ }^{11}$. El arte contemplativo será sólo una vía momentánea de reposo, en el fondo un espejismo. Sólo en el sentido de la voluntad imparable de dos sujetos amantes que desean buscar una atmósfera propicia para ser uno -ellos creen que en la noche-, sólo en este sentido, decimos, es deudor Tristán e Isolda de la filosofía de Schopenhauer.

El mundo como voluntad y representación ve la luz en 1819 y sabemos con certeza que Wagner conocía bien la obra. Pero ya cargado de años, en 1844 Schopenhauer escribe sus Complementos a su obra de $1819^{12}$, de una extensión similar a esta. En estos Complementos Schopenhauer habla del amor entre hombre y mujer, cosa de la que en realidad apenas había hecho mención en su primera obra de 1819. Schopenhauer insiste de forma materialista en que el enamoramiento, su elevación y sacralidad esconde sólo el fin de la procreación del hijo, la conservación y extensión de la especie ¿Conocía Wagner las reflexiones de estos Complementos? No lo sabemos con certeza. Sabemos que estas extensas adiciones fueron escritos en 1844, sabemos que Wagner leyó El mundo como voluntad y representación en 1854 y sabemos que en 1865 Nietzsche se apresuró a hacerse con una edición conjunta de la obra de Schopenhauer -que incluía los Complementos- ${ }^{13}$. Pero si la edición de la obra de Schopenhauer que Wagner leyera en 1854 incluía o no estas reflexiones sobre el amor expuesta

[11] En otro trabajo nuestro (Cf. Ríos Rojas, A: Parsifal o la ineficacia de la compasión. Revista de Occidente; junio, Madrid, 2014, p.61-85) tratamos de mostrar al Parsifal de Wagner -contrariamente a la opinión general establecida- como una obra fiel a la filosofía de Schopenhauer. Ahora hacemos -desde el más pronfundo convencimiento- un ejercicio en sentido contrario, tratando de presentar que la considerada más schopenhaueriana de las obras de Wagner, Tristán e Isolda, si bien coincide en muchos aspectos con la filosofía de Schopenhauer, se aleja en no pocos de los pensamientos del filósofo de Danzig.

[12] Bien es cierto que la obra de 1819 va siendo progresivamente modificada hasta la ampliación que tiene lugar con los Complementos.

[13] Safranski, R: Nietzsche. Biographie seines Denkens. Fischer Verlag, Frankfurt, 2008. p.132.

THÉMATA. Revista de Filosofía, No51 enero-junio (2015) pp.: 343-361

doi: 10.12795/themata.2015.i51.18 
en los añadidos de 1844, no lo sabemos. En 1865 se estrena el Tristán, pero la obra ya estaba concluida en 1859. Wagner y Nietzsche bien pudieron haber comentado años después, durante sus largos paseos alpinos, estas reflexiones de los Complementos. De todos modos,los conociera o no Wagner antes de escribir el Tristán, el hecho es que cuando Tristán e Isolda se miran, cuando ambos aman, no existe ni por asomo lo que Schopenhauer destaca en su obra de 1844: Ya en el encuentro de sus anhelantes miradas se enciende la vida del hijo... Los amantes sienten el anhelo de fundirse realmente en un solo ser, para luego proseguir viviendo sólo en él y este anhelo se colma en lo generado por ellos como aquello en lo que se transmiten las cualidades e ambos para sobrevivir fusionadas y reunidas en un ser ${ }^{14}$.

En la ópera de Wagner jamás se habla de este fruto del amor. Unos verán en ello la "modernidad" de Wagner en tanto el amor no queda sujeto a la procreación; otros, en cambio, verán su extrema idealidad respecto al amor. Siguiendo con nuesta metáfora respiratoria, el hijo podría significar en Tristán e Isolda una ventana abierta por donde sopla el aire, por donde el aliento de Tristán y de Isolda se airean y se tornan salubres. Sin embargo, el goce cerrado entre dos es lo que tiene lugar en el Tristán.

Aunque no haya faltado quienes condenen este fruto material del amor -el hijo- como lo que vicia y destruye el amor -pensamos, por ejemplo, en La sonata a Kreutzer de Tolstoi- creemos que este tercero permite el acceso de aire y por lo tanto de salubridad e higiene en teoría la relación a dos, a veces con tempestades, a veces con brisas, pero este tercero permite la entrada de aire. Este es el motivo por el que la ingeniosísima teología cristiana necesita de un tercero para que pase aire, y nunca pudo quedar mejor expresado este tercero como de hecho ha quedado expresado en la teología cristiana, como "Espíritu" -pneuma, aire-. Este pensamiento teológico-mágico siempre deja mayor aire entrante y saliente -conceptualmente al menos- que la asfixiante "binidad" islámica o judía: Dios-Libro. Wagner en su Tristán prescinde del tercero, prescindiendo con ello del aire, por eso se sitúa esta ópera tan próxima a la disolución, no sólo de Tristán y de Isolda, sino del mundo mismo, de la especie humana. Como señalaremos más adelante hay indicios sombríos en el Tristán de una insinuante invitación al suicidio colectivo de la especie humana. Wagner mismo sabía más que nadie de la peligrosidad de su Tristán y así lo deja ver en una carta a Mathilde Wesendonk, que dicho sea de paso, es la amada real, la Isolda en la que piensa el Tristán Richard Wagner. La carta recogida por Safranski dice así: Este Tristán e Isolda es lo más terrible...Este último acto!!! Temo que la ópera sea prohibida a menos que se interprete como una parodia; una gran interpretación debería enloquecer a la gente. ${ }^{15}$

[14] Schopenhauer, A: El mundo como voluntad y representación. Vol. 2; Complementos, FCE, 2003; p.518.

[15] Safranski, R: Romantik; Fischer Verlag, Frankfurt am Main, 2010, p.273. La traducción es mía.

THÉMATA. Revista de Filosofía, No51 enero-junio (2015) pp.: 343-361

doi: 10.12795/themata.2015.i51.18 
Digamos ahora, a modo de relajación ante tanta tragedia, en un tono humoresco -o indignante para quien no pueda tomarlo con humor- que, si la influencia de las ideas schopenhauerianas sobre el amor humano se hubieran visto reflejadas en el Tristán de Wagner, tendríamos que el verdadero héroe de la ópera sería Tristán y no Isolda, pues siguiendo las ideas de Schopenhauer sobre el amor, la mujer, al unirse fielmente a uno y al mismo hombre sigue a su naturaleza, mientras que al hombre le es natural la infidelidad y la inconstancia ${ }^{16}$.

Tampoco encontramos en la ópera de Wagner aquel amor del que Schopenhauer habló en su obra original de 1819, es decir, el amor puro y verdadero como compasión. La compasión es capacidad para sentir el sufrimiento ajeno. A Tristán e Isolda les está negada la compasión, el altruismo, y no son capaces de reconocer el dolor del mundo. Son ciegos para ver la "identidad" de la voluntad en todos sus fenómenos, en todo ser vivo. No pueden reconocer la identidad del sufrimiento en todo ser. El rey Marke, Brangania y Kurwenal, personajes bondadosas y fieles los tres, apenas cuentan en la ópera; son fantasmas, voces cuyo contenido no son oídos por la pareja protagonista. Ni siquiera el conmovedor monólogo del rey Marke hace efecto alguno. Mozart supo dar efecto e influencia moral a la voz de Sarastro en La flauta mágica, Marke y su discurso moral, son en cambio meros espejismos ilusorios. Todo amor puro $y$ auténtico es compasión y todo amor que no sea compasión es egoismo ${ }^{17}$.

Pero Wagner sí hace una operación en la filosofía de Schopenhauer, operación con la que mantiene las ideas del filósofo, al equiparar el fin del amor pasional de Tristán e Isolda con el fin del amor compasivo, pues ambos fines son el mismo: la disolución, la muerte, la nada. Wagner sabrá que alcanzar lo que el querer quiere, satisfacer el querer, alcanzar la plena unidad amorosa, la eterna y constante plenitud de amor sólo es posible con la muerte, pues la vida no tiene descanso por mor del querer. La fusión hace el efecto de anulación, de desintegración. Pues la voluntad, que implica siempre una carencia, compete

[16] Para no dejar vacío el pensamiento mismo de Schopenhauer, y para distender tanta tragedia y disolución, citaremos al mismo autor: El amor del varón disminuye notablemente desde el momento en que ha recibido satisfacción: casi cualquier otra mujer le excita más que la que ya posee, y anhela la diversificación. En cambio el amor de la mujer aumenta desde ese mismo instante. Esto es una consecuencia del fin de la naturaleza, que se orienta hacia la conservación y al máximo incremento de la especie. El hombre puede procrear cómodamente más de cien hijos en un año, con tal de tener a su disposición otras tantas mujeres; en cambio, la mujer, aún cuando tenga ese mismo número de hombres, sólo puede traer al mundo un hijo por año (sin contar el nacimiento de gemelos). Por eso él mira continuamente alrededor otras mujeres, mientras ella se aferra a un solo hombre: pues la naturaleza le impulsa, instintiva e irreflexivamente hacia quien ha de alimentar y proteger a la futura prole para conservarla. Con arreglo a ello la fidelidad conyugal es artificial para el hombre y natural para la mujer, por lo cual el adulterio de la mujer es mucho más imperdonable que el del hombre, tanto objetivamente, por las consecuencias, como subjetivamente, por ser contrario a la naturaleza. (Cf. Schopenhauer: o.c; Vol 2; p.524-525).

[17] Schopenhauer, A: o.c; Vol 1; p.477

THÉMATA. Revista de Filosofía, Nº51 enero-junio (2015) pp.: 343-361

doi: 10.12795/themata.2015.i51.18 
al individuo. Es por ello que, en el fondo, existe una tendencia trágica de Tristán y de Isolda a convertirse en sujetos avolitivos del conocimiento, tal como pensaba Schopenhauer que acontecía en las grandes obras del genio artístico. El tormento-gozo para ellos radica en que amar, querer de pleno y sin descanso significará morir, disolverse el uno en el otro. Wagner lleva aquí el sentimiento amoroso a su extremo, no hay medianías, y el amor, si es extremo, no sólo está emparentado con la muerte, sino que implica la muerte misma.

Tristán e Isolda no beben la pócima del amor, sino la de la muerte. Brangania no ha cambiado la pócima de la muerte por la del amor, sino la de la muerte rápida por la de la lenta. La apropiación mutua, la carencia de límites entre ellos mismos y entre lo externo, que ya no existe para ellos, eso mismo es la muerte. Y esto es lo que atisbamos en la vida de los místicos y en su anhelada unión a Dios; unión sólo y exclusivamente con el esposo, tal como pretendía Santa Teresa. Atendiendo a las palabras con las que Schopenhauer cierra su cuarto libro de $E l$ mundo como voluntad y representación, estos pensamientos nuestros sobre la unión mística y la muerte encuentran su apoyo. Gracias a la consideración de la vida y el comportamiento de los santos...que nos pone ante los ojos el arte, tenemos la oscura impresión de esa nada, que como última meta se cierne tras toda virtud y santidad. Más bien confesamos con toda franqueza que tras la total supresión de la voluntad y para todo lo que no esté todavía lleno de esa voluntad misma no queda sino la nada. Pero también a la inversa, para quienes han dado la vuelta y negado a la voluntad, este mundo nuestro tan real, con todos sus soles y galaxias, no es nada ${ }^{18}$.

El segundo acto de Tristán e Isolda es el acto en el que realmente la droga actúa en su máximo efecto. Es el acto de la noche de amor, el más apasionado de los tres actos de la ópera. La pasión se mantiene aquí porque de fondo se mantiene el límite, es decir ambos saben que tras esa noche de amor infinita vendrá el día, se presentará el rey Marke y lo que implica: la moral, el deber, el honor, la apariencia. Saber que el límite-día vencerá al límite-noche hace que el dúo "Isolde, geliebte...Oh sink hernieder, Nacht der Liebe... einsam wachend in der Nacht..." Isolda, amada, vayamos a las profundidades, a la noche de amor, despertemos solitarios en la noche", esté penetrado aún de pasión, y es sólo al final del dúo, al aproximarse el día, cuando ambas voces entran en una cadencia drogada, en un dejarse llevar como presagio de que la muerte que tendrá lugar en el tercer acto será dulce. En ese final del segundo acto, nace el día nuevamente. Se aproxima como verdugo, y es la sospecha de su inmediata presencia lo que tranquiliza resignadamente a la pasión, haciendo por vez primera que Tristán e Isolda sean realmente uno, como decimos, en pregasio de la muerte dulce con la que termina la asfixia. Se anticipa una carencia ya de agonía al ver cercano al verdugo-amanecer y todo se colma de tranquilidad y de

[18] Schopenhauer, A: o.c; p.516.

THÉMATA. Revista de Filosofía, Nº51 enero-junio (2015) pp.: 343-361 doi: 10.12795/themata.2015.i51.18 
sereno hundimiento al final de este dúo de amor del acto segundo. El día hace ver el espejismo de la noche eterna, y será reconstruído el velo que el amor-infinitud-noche había creído rasgar. Velos opacos vuelven a tapar el gozo de la inconsciencia, estados de sobriedad vuelven a vencer a la embriaguez del amor.

El que ambos se nieguen a que el día aparezca es ya una notoria y velada declaración de un suicidio colectivo a dos. Y Wagner sabe hacer con esas melodías infinitas, en acordes interminables a través de las voces cansinamente enfermas y drogadas, que el oyente-espectador comprenda con serenidad estoica la apacible muerte que se avecina, que no es sino la única solución a la pasión verdadera.

\section{Interludio. El anillo del nibelungo y tristán e isolda}

Con el mismo "leit motiv" respiratorio, tomamos ahora la comparación del Tristán con la Tetralogía El anillo del Nibelungo. La monumental obra que es El Anillo, compuesta por El oro del Rhin, La Walkiria, Sigfrido y El ocaso de los dioses representa mejor que ninguna otra obra del compositor su anhelo de unión político-artístico, no sólo en la composición musical-dramática en sí, sino en su contenido textual. Aunque Tristán e Isolda se estrenara en 1865 y el Anillo viera su estreno en 1876, la verdad es que en el proceso compositivo de Wagner ambas obras se entrecruzan, incluso el Anillo es en concepción y comienzo muy anterior al Tristán. Ya en 1848, el año clave para la vida de Wagner y sus ideas revolucionarias -fracasadas- comienza su esbozo del Anillo, mientras que el Tristán es concebido y comenzado en 1856, quedando concluído en 1859.

Tristán e Isolda es la menos revolucionaria de sus obras en cuanto a contenido ideológico, no así en cuanto a música y drama, verdadero antes y después de la historia de la música. El Anillo es en cambio, la más revolucionaria en cuanto a ideas. El deseo revolucionario de Wagner de unir a la sociedad con el arte $^{19}$, y que sean los mitos el anclaje de ello, es el proyecto de El Anillo. Una unión para la vida, para una vida más plena también en sociedad es lo que persigue El Anillo. Sin embargo el sabor a derrota que se respira en el Tristán es portentoso; aquí se rechaza y se niega de hecho toda posible unión social. Los contrarios en el Tristán son ineludibles, eternas luchas sin descanso: noche-día; sueño-deber... Hemos señalado que la atmósfera asfixiante del Tristán consiste en un mundo dual, noche y día, incluso Tristán e Isolda, pues el prescindir de la "y" resultará un sueño imposible, como veremos en nuestro apartado "suicidio". El vencimiento del hombre sobre su propio "extrañamiento" sólo se consigue con el hundimiento. El que no haya un mundo intermedio, la carencia de intermediarios, el "mundo a dos" es lo que nos asfixia en el Tristán. Sin embargo en el Anillo podemos respirar aunque nos encontremos en las

[19] Wagner, R: Gesamte Schriften und Dichtungen Olms; Hildesheim, 1976; Vol.3 p.105-136.

THÉMATA. Revista de Filosofía, Nº51 enero-junio (2015) pp.: 343-361

doi: 10.12795/themata.2015.i51.18 
profundidades del Rhin, porque el Anillo está pensado "a tres" y si apuramos "a cuatro". En El Anillo tenemos como primer nivel el mundo de los fondos, que significa la pureza, amor y la belleza, representadas por las hijas del Rhin.. Ellas pueden mirar el oro sin deseo de poseerlo (tal como Schopenhauer decía que debía ser el carácter sublime), no custodian el oro, sino que lo contemplan como lo que da luz en las profundidades. El segundo nivel queda representado por el mundo de los Nibelungos: poder, posesión, esclavitud, el tercer nivel lo representa el mundo de los Welsungos, Siegmund, Siegfried, Siegliende, y como cuarto nivel encontramos el mundo de los dioses, los cuales han traicionado su unión pura con respecto al primer mundo puro de las profundidades. Los Welsungos darán muerte a los dioses corruptos para que surja un mundo nuevo, Sigfrido es este héroe por antonomasia. A través de Sigfrido, Wagner habla como un héroe clásico. Mientras el héroe romántico muere por amor, el héroe clásico vence, deslegitima y mata. Pero del héroe romántico guarda Sigfrido una propiedad, el anhelo de unión salvífica del hombre con su mundo entorno, ni días ni noches, ni estructuras binómicas antirespiratorias, sino un mundo uno posibilitado por infinidad de mundos, de ventanas que, o se han abierto demasiado o no se cerraron como debían. Sigfrido une no ya sólo noche y día, sino poder y amor. El poder social y político, de eso se trata también en el Anillo, pues Wagner no entiende la política de la forma tan positivista y racionalista que nosotros la entendemos, sólo como campo del avance y del progreso, el progreso es para Wagner también el retroceso ${ }^{20}$.

El Tristán, sin embargo, opera sólo en dos niveles: el primero representado por los fondos, la noche en la que quieren hundirse los amantes como símbolo de pureza y el segundo representado por el mundo humano como poder, apariencia, espejismo, moral, esclavitud. No hay otro acto heroico en el Tristán que el suicidio a dos. Tristán e Isolda son la negación de Sigfrido. La victoria de Sigfrido es sobre sí mismo, el hombre se vence a sí mismo, venciendo a los dioses, que no son sino sus proyecciones en ansias de poder ${ }^{21}$. En cambio, Tristán e Isolda se derrotan voluntariamente a sí mismos, convirtiéndose en los héroes suicidas.

\section{Suicidio}

Por lo general el romántico se suicida no por amor sino por imposibilidad de plenitud de amor o, sobre todo, por desamor. A través del suicidio el romántico busca una unión más pura y eterna, con el todo, con el alma del mundo, con la tierra, con el pasado, con los muertos. El suicidio es pues refugio, huida sublimada ante el desamor. En la muerte de amor del molinero en

[20] Wagner, R: o.c; Vol.4, p.55-57.

[21] Safranski recuerda que Wagner idea su anillo en clave feuerbachiana. Cf. Safranski: o.c; p. 263.

THÉMATA. Revista de Filosofía, Nº51 enero-junio (2015) pp.: 343-361

doi: 10.12795/themata.2015.i51.18 
los poemas de Wilhelm Müller, inmortalizado por Franz Schubert en La bella molinera, el molinero se funde en su muerte con el arroyo como símbolo del eterno fluir del todo, y es el todo, el arroyo, el que como venganza visita a la amada, quien ha preferido al cazador y no al poeta, diciéndole: "no molestes más al molinero, que no le pise tu sombra". Esto es muerte por desamor, tal como en el Werther de Goethe, como en el Hyperion de Hölderlin. Nadie puede amar al romántico, pues la plenitud que él desea es irrealizable. Sin embargo en Tristán e Isolda no se produce desamor ni amor finito, sino el anhelo de un amor perfecto, de una simbiosis plena, siéndoles para ello la luz un estorbo, una instancia a superar. El día es el enemigo. Les "asfixia" la luz que es el origen del aire respirable de la atmósfera-quizás Wagner no conocía este detalle científico, pero lo intuyó de algún modo-. Se niega por tanto el aire y la luz. Se prepara un suicidio colectivo a dos. Podemos imaginar que Schopenhauer ya se refería a la locura wagneriana cuando en 1844 escribía: Cada año muestra algún que otro caso de suicidio simultaneo de una pareja cuyo amor se ha visto obstaculizado por circunstancias externas, aunque a mi me resulta inexplicable cómo quienes, seguros de su mutuo amor, esperando encontrar en el disfrute de éste la dicha suprema, no prefieran sustraerse a todas las componendas externas y soportar cualquier infortunio antes de renunciar con la vida a la mayor felicidad imaginable para ellos ${ }^{22}$.

Retornemos a la sinopsis de la ópera: Tristán conduce la nave que lleva a Isolda hacia el reino de Marke, con quien deberá desposarse. La nave es conducida con un tiempo propicio. Wagner no utiliza aquí la tempestad con la que Verdi hace llegar el barco que lleva a Otello a Venecia. La calma en el barco de Tristán es, en cambio, abrumadora, premonición del Hades griego, acompasado por la canción del marinero, terrible en su portentosa calma, como si lentamente condujera Caronte la barca hacia el Hades. Así comienza la primera escena del primer acto de Tristán e Isolda. Tristán guarda en este primer acto un silencio apesadumbrado, una especie de estado depresivo, pues ya ha quedado preso del amor a Isolda -aunque sólo un atento intérprete de la obra cae en la cuenta de ello-, ese amor ya lo siente en el reino del día, desde aquella vez que sus ojos se encontraron. Isolda está en otro estado, menos depresivo y más ansioso. La pasión de Isolda, igualmente despertada ya cuando los ojos de ambos se miraron, tiene a su mano motivos más fáciles para encubrir el amor: el gran motivo del odio. Ahora el amor callado y no desvelado de Isolda encuentra en el odio su aliado, su cobertura más perfecta. Isolda sabe que Tristán es el asesino de Morold y planea su muerte y de paso la suya propia, pues no desea desposarse con Marke y, aunque no declaradamente, ya es esclava del amor hacia Tristán.

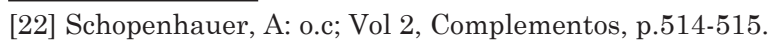

THÉMATA. Revista de Filosofía, Nº51 enero-junio (2015) pp.: 343-361

doi: 10.12795/themata.2015.i51.18 
El silencio apesadumbrado de Tristán, el odio encubierto de Isolda les prepara a ambos para un sentimiento que no les librará del suicidio. Es más, Isolda ya está dispuesta a suicidarse ella misma al ofrecer para ambos la pócima de la muerte.

El estado de ánimo de ambos es ya tendente en la primera escena de la ópera a la desolación y próximo al suicidio. La sustitución que Brangania hace de la pócima no altera nada, sino que, como hemos dicho, sustituye la muerte rápida por la lenta, hará que el suicidio lo sea al modo del arte, el morir por amor, por unidad monstruosa.

Tristán morirá a manos de Melot, pero es él quien se lanza hacia la espada de su enemigo, suicidándose en realidad. Hubiera cabido esperar el perdón del buen rey Marke hacia Tristán. Marke estará dispuesto a perdonar el que su fiel Tristán se haya apoderado sentimentalmente de Isolda -de hecho el perdón de Marke tendrá lugar-, pero Tristán no quiere saber nada de ese perdón, y se hunde voluntariamente sobre la espada de Melot. Sin embargo, la tendencia al suicidio tras el sentimiento apasionado del amor puede tener un fin feliz, se ofrece una esperanza. En el tercer acto Tristán, ya herido, es conducido a Kareol por Kurwenal, éste espera que allí el sol, la luz y las praderas ayuden a la recuperación de Tristán. Isolda se ha hecho a la mar hacia Kareol para unirse con Tristán. Aparece por un momento la posibilidad de la felicidad, de un amor en la luz. Pero ellos lo rechazan de lleno. Se niegan a alzar la cabeza hacia la luz, prefieren hundirse en el gozo vampírico en el que ambos se sorben la sangre mutuamente, en el que mutuamente se devoran. Cuando Isolda llega a Kareol deja ver su obsesiva locura: "No mueras por la herida -le dice a Tristán- muere de amor conmigo". "Deja que cure tu herida para que sanos y salvos compartamos la noche". Aquí se hace evidente que compartir la noche es morir. Para Isolda no morir en la noche junto a Tristán es la verdadera tragedia. Morir por separado y no morir Uno es el drama de Isolda. Es capaz hasta de llamar a Tristán "infiel" por no morir junto a ella en disolución amorosa ${ }^{23}$. El "demasiado tarde" que repite Isolda al final de esta última escena no quiere lamentar la muerte de Tristán, sino el no morir juntos. "He venido por mar para contraer contigo un feliz enlace". Si son uno, si se ha anulado la conjuntiva " $y$ " tienen necesariamente que morir juntos, de no ser ello así se demuestra la fantasiosa, quimérica idea de ser Uno. Kleist en su "Pantasilea" hace que la protagonista descuartice y se coma de amor a su amado, en un caso de antropofagia amorosa romántica en el que se manifiesta el ansia de unidad con el amado, verdaderamente sólo así tiene lugar unidad, en un proceso alimenticio-digestivo, recreador ${ }^{24}$. Como el vientre de la mujer lleva en su seno al hijo, Pantasilea lleva en su seno como alimento a su amado.

[23] Estas reflexiones las vio ya muy bien Eugenio Trías. Cf,Trías, E: o.c; p.77.

[24] Kleist:, H. von: Panthesilea; Insel Verlag, Frankfurt, 1980, p.143.

THÉMATA. Revista de Filosofía, Nº51 enero-junio (2015) pp.: 343-361 doi: 10.12795/themata.2015.i51.18 
No en vano el cristianismo cree que en la unión eucarística el creyente se hace Uno con Cristo al ingerirlo, en clara reminiscencia antropofágica. Pero al menos en la obra de Kleist hay alguien que lleva el mando, Pantasilea es la que se come a Aquiles y no al revés. Tristán e Isolda desean asfixiarse juntos, respirar juntos y asfixiarse juntos. La muerte debe ser de ambos al mismo tiempo. Sólo cuando ha fracasado la muerte junto a su amado es cuando Isolda es consciente de su individualidad, y sólo entonces tiene lugar en ella el sentimiento filosófico romántico por excelencia: no la muerte junto al amado-uno, sino la unión con el todo en la muerte, sólo cuando ya no está Tristán junto a ella puede desear el aliento infinito del alma universal en el que ella quiere fundirse. "Hundirse, anegarse en las olas, en las grandes olas del mar de delicias, en la sonora armonía de hondas de perfume, en el aliento infinito del alma universal, perderse, abismarse, isupremo deleite!' Lo que Schopenhauer quería que aconteciera por dolor del mundo y compasión, acontece en Isolda por depresión honda ante la imposibilidad del amor eterno. Trías ha interpretado la muerte de Isolda quizás bajo la influencia romántica de Novalis o Hölderlin y habla de muerte en ascensión hacia el espacio-luz. Creemos, sin embargo, que esto no lo deja ver Wagner, quien insiste en la imagen no del ascenso, sino del hundimiento. $\mathrm{Al}$ igual que los escenógrafos de ópera se permiten licencias interpretativas -algunas horrendas- nosotros hacemos ahora de escenógrafos y modificamos la escena en la que el moribundo Tristán, en brazos de Isolda, exhala junto a su boca la palabra: "Isolda". El inspirar esta palabra por parte de Isolda es lo que causa su muerte. "Isolda", solo Isolda queda. Nuestra puesta en escena no insistiría en el concepto de "exhalar" un aliento, sino de extirpar un miembro. El miembro siamés Tristán es el que corta la respiración definitivamente al miembro siamés Isolda. No es tanto un exhalar aliento sino un corte, una extirpación de una esencia monstruosa. Un escenógrafo atento a esto haría que con la palabra "Isolda" pronunciada por Tristán, Isolda hiciera gestos de dolor monstruosos y espasmos de tipo epiléptico.

\section{La noche}

Tristán e Isolda es la obra del amor-pasión por excelencia, pero es también la obra en la que la noche y la oscuridad se convierten en la única atmósfera amorosa y en el único refugio para el amor. Respecto a la noche, Wagner encuentra un apoyo mayor en la filosofía romántica que en el propio Schopenhauer, su deuda con Novalis, por ejemplo, es enorme.

El conocedor de la filosofía de Schopenhauer que fue Wagner pasó por encima de las reflexiones del filósofo acerca de la luz, del día y de la claridad. Sobre todo porque las más decisivas reflexiones sobre la luz y el día que tienen lugar en El mundo como voluntad y representación son expuestas en el Libro III de esta obra, en un marco de filosofía contemplativa y apolínea de lo ideal. 
Pensamientos como los que a continuación traemos son impensables en el marco del Tristán: Lo que para la voluntad es el calor es la luz para el conocimiento. La luz es el diamante más grande en la corona de la belleza y posee la influencia más decisiva sobre el conocimiento de cada objeto bello; su presencia es una condición indispensable y su oportuno emplazamiento realza la belleza de lo más bello ${ }^{25}$. La luz es la más alegre de las cosas: se ha convertido en símbolo de todo lo bueno y todo lo saludable...la ausencia de luz nos entristece de inmediato, su retorno nos alegra ${ }^{26}$.

Rechazando la luz, Wagner rechaza la belleza y el conocimiento de lo bello, en el ansia de Tristán y de Isolda de vivir en la oscuridad está el ansia de entregarse a sentidos más primitivos que el sentido de la vista, por el que percibimos la luz. Para ellos el tacto, el olor, el sabor, el oído, son los verdaderos sentidos y la visión sólo un sentido a medias. A los siameses unidos por la boca no les sirve la visión. Las palabras de Tristán en el segundo acto: "Se ve a través de la noche", son, desde nuestro entendimiento de la ópera, inexactas, y deben ser entendidas sólo metafóricamente, pues no es exactamente "ver" lo que quiere Tristán, sino dejar de ver. Sin embargo, no hay error cuando Novalis nos dice en su Himno I que los ojos que la noche ha abierto en nosotros ven más allá que la luz, pues Novalis aspira realmente a ver -lo trataremos de inmediato- y no así Tristán e Isolda. Ellos son y quieren ser eternos ciegos, su ver es sólo ese modo dionisíaco de saber que hace que el sentido de la vista quede superado por otros sentidos más primigenios.

La obra de arte que es el Tristán muestra, sin embargo, que el arte es algo a prescindir, al menos en su esfera "pura", intuitivo-contemplativa; a los amantes sólo les preocupa la voluntad, el amarase sin descanso, y eso es ya contrario al arte intuitivo, luminoso, contemplativo, que requiere de la suspensión de la voluntad y que se da sólo en instantes. Ni el conocimiento ni el instante, sino la pasión y la eternidad es lo que buscan Tristán e Isolda. Tristán e Isolda son seres que se niegan a elevar la cabeza, a ver la luz. El erguimiento biológico de la cabeza propio de la especie humana también podría ser, según la filosofía de Schopenhauer, un indicio de que el ser humano -siendo todo él y todos sus miembros físicos voluntad-, es también conocimiento, de que la voluntad también queda en el género humano elevada al conocer y puede reposar, al menos por instantes, en el conocer puro. Sin embargo, una y otra vez se repiten en la ópera los términos, "versinken", "ertrinken" -hundirse, ahogarse-. La noche es el símbolo mayor del hundimiento, al hundirse en ella el órgano artístico apolíneo y cognitivo puro, la visión. Que lo amorfo triunfe ante la forma, que Dionisos triunfe ante Apolo es el anhelo de Tristán ¿Qué atmósfera mejor para anular las formas que la oscuridad?

[25] Schopenhauer, A: El mundo como voluntad y representación; edic.citada, p.294.

[26] Schopenhauer, A: o.c, p.291.

THÉMATA. Revista de Filosofía, Nº51 enero-junio (2015) pp.: 343-361

doi: 10.12795/themata.2015.i51.18 
Pero por todo lo que hemos venido ya comentando, la noche significa el escapar de una condena, la condena del día y de la luz, también la condena del tiempo pues el día significa temporalidad -Novalis en sus Himnos a la noche caracterizó al día con el artificio del reloj ${ }^{27}$, mientras que la noche es eternidad suspensión del tiempo y el espacio. Sin tiempo y sin espacio es el reino de la noche (Himno II). La preferencia de la noche, de lo telúrico, de la oscuridad, de lo inconsciente creador, del silencio nocturno, de la suspensión de espacio y tiempo que en la noche se produce es algo común a los románticos, pero pocos como Wagner han separado de una forma tan irreconciliable noche y día, luz y oscuridad. Así lo expresa Albert Beguin: Lo que los románticos quieren no es abandonarse sin resistencia al Inconsciente creador, sino apoderarse de él, elevarlo a la conciencia hasta el día en que una magia superior consume la reconciliación inal $^{28}$. Reconciliación entre noche y día. Esta es la clave buscada por el romántico, los más pesimistas de entre ellos lo verán como una quimera, otros seguirán refugiándose en la noche para ver en ella los signos de unión, de reconciliación entre la luz y la oscuridad, entre las fuerzas inconscientes y la conciencia del hombre. Argullol ha señalado a Apolo como un dios modelo también para el romántico -y no sólo Dionisos-, sin embargo Argullol piensa que Apolo viene a ser el "principium individuationis" para los romántico; nosotros, tomando las ideas de Argullol, decimos que lo apolíneo está en la forma y reconciliación final del todo. La compasión ante el dolor del mundo y el deseo de reconciliarlo -religiosamente como en Novalis, p.e- es una forma también de sentimiento apolíneo, sentimiento apolíneo al que Nietzsche redujo sólo a la forma bella.

El romántico busca la edad de oro perdida, la edad de oro apolínea. Hölderlin y el mago cristiano Novalis acuden a edades de oros griegas, a mitos primigenios en los que la madre tierra cohabita en paz y armonía con lo emanada de ella, la luz y el día. Esta es la situación que también Wagner expresa en el Anillo del Nibelungo, antes de que Alberich sacrificara el amor por las riquezas $\mathrm{y}$ antes que los dioses esclavizaran a los gigantes para su propio provecho.

Pero en el Tristán la reconciliación se hace imposible. Luz y oscuridad no desean ya cohabitar juntos, pues el amor del que se trata en Tristán e Isol$d a$ es un amor mucho más estrecho que el amor romántico. En el amor romántico la amada puede ser luz, pero luz que refleja una luz superior. Recordemos que Novalis ve a su amada muerta a los quince años, Sophie von Kuhn, venir en la noche de la mano de Cristo ${ }^{29}$. En Novalis y en la mayor parte de los románticos el amor es un amor cósmico, una unión universal con lo perdido, con el alma del mundo del que somos parte. Para Novalis la noche es el único

[27] Cf. Novalis: Himnos a la noche y Cántico espiritual; Círculo de lectores, Barcelona, 2001; p.29.

[28] Beguin, A: El alma romántica y el sueño; FCE, 1978; p.111

[29] Cf. Novalis: o.c; p.43.

THÉMATA. Revista de Filosofía, Nº51 enero-junio (2015) pp.: 343-361

doi: 10.12795/themata.2015.i51.18 
camino para descubrir la luz. La luz sola, el día y sus trajines ciegan, la noche abre los sentidos. De ahí que Novalis reclame al Padre -al Dios cristiano- que da figura a la claridad divina, conciliación de la luz y la sombra. En el seno de lo absoluto se da para los románticos la unión de los contrarios. Novalis habla siempre de "más allá", de "el otro lado", Novalis juega con conceptos como elevación y hundimiento, unas veces utiliza el primero, otras el segundo. Esto es así porque en el poeta se espera este otro lado, este más allá que reconcilia día y noche, por ello a veces se expresa con el término "hundimiento", y otras con "elevación". Todo es hundimiento en Tristán e Isolda. La noche es el estado del amor egoísta, de la masa ciega a dos. No existe memoria en la noche para los dos amantes wagnerianos, mientras que en los románticos la noche es el espacio en el que cerrando los ojos uno se encuentra con lo sido, con la memoria, con los muertos. "Cerrad los ojos y veréis"; "Antes de abrir los ojos ya lo sé todo de memoria" ${ }^{\prime \prime 0}$. Los románticos huyen del día porque este separa más y ellos se esfuerzan en buscar ese estado originario antes de la separación. El romántico huye del día porque este le separa más, ya que el día es progreso, seguir hacia delante y este seguir hacia delante separa más de la unión con todo lo sido, con la visión del útero, del abrigo universal del todo-uno. Mientras el puro romántico quiere parar, cerrar los ojos para ver, Wagner no desea parar y cerrar los ojos para ver sino hundirse para dejar de ver. La locura del Tristán consiste en un "arrancarse los ojos", y esto es así porque Wagner en el Tristán es ajeno a la unidad cósmica, al adviento que tiene lugar sólo en la Noche como noche oscura, como vía para ver de nuevo la luz. No es sólo una metáfora que Novalis dijera a la noche: "Noche, tú abres las puertas del cielo"’31. Wagner en el Tristán no es un místico, ni tan siquiera un filósofo romántico, es más bien un rotundo nihilista.

[30] Frases de Joubert y Claudel citadas por Beguin en o.c; p.109.

[31] Cf. Novalis: o.c; p. 45

THÉMATA. Revista de Filosofía, No 51 enero-junio (2015) pp.: 343-361 doi: 10.12795/themata.2015.i51.18 


\section{Referencias bibliográficas:}

Argullol, R: El héroe y el único; Acantilado, Barcelona, 2008.

Beguin, A: El alma romántica y el sueño; FCE, 1978.

Canetti, E: Masse und Macht; Büchergilde, Frankfurt am Main, 1988.

Kleist, H. von: Panthesilea; Insel Verlag, Frankfurt, 1980.

Mann, T: Freud, Goethe, Wagner, Tolstoi; editorial Poseidón, Buenos Aires, 1944.

Novalis: Himnos a la noche y Cántico espiritual; Círculo de lectores, Barcelona, 2001.

Ríos, A: Parsifal o la ineficacia de la compasión. Revista de Occidente; junio, Madrid, 2014.

Trías, E: Tratado de la pasión. Debolsillo; Barcelona, 2006.

Safranski, R: Romantik; Fischer Verlag, Frankfurt am Main, 2010.

Safranski, R: Nietzsche. Biographie seines Denkens. Fischer Verlag, Frankfurt, 2008.

Schopenhauer, A: El mundo como voluntad y representación FCE, 2003.

Sloterdijk, P: Esferas III; Siruela; Madrid, 2006.

Strassburg, G. von: Tristán und Isolde. Verlag Neues Leben, Berlín, 1975.

Wagner, R: Gesamte Schriften und Dichtungen Olms; Hildesheim, 1976.

\section{TRISTÁN E ISOLDA EN DVD.}

En CD tenemos innumerables versiones, nos limitaremos a dar tres en DVD que son de nuestro gusto.

- Deutsche Grammophon. Bayreuth, 1983. Puesta en escena de Jean-Pierre Ponelle; director musical: Daniel Barenboim. Tristán: René Kollo, Isolda: Johanna Meier

- Virgin classics. La Scala, 2007. Puesta en escena de Patrice Chéreau; director musical: Daniel Barenboim. Tristán: Ian Storey, Isolda: Waltraud Meier.

- Deutsche Grammophon. Metropolitan, 2004. Puesta en escena: Brian Large; director musical: James Levine. Tristán: Ben Heppner; Isolda: Jane Eaglen 
